\begin{tabular}{|c|c|c|c|c|}
\hline & & $R^{1}$ & $F_{i}^{2}$ & $R^{3}$ \\
\hline & I : & $\mathrm{H}$ & $\mathrm{Me}$ & $\mathrm{M}_{\Theta}$ \\
\hline & II : & $\mathrm{Me}$ & $\mathrm{Me}$ & $\mathrm{Me}$ \\
\hline $\mathrm{C}-R^{2}$ & III : & $\mathrm{Ph}$ & $\mathrm{Me}$ & $\mathrm{Me}$ \\
\hline 1 & IV : & $\mathrm{Ph}$ & Et & $\mathrm{Me}$ \\
\hline$R^{1-1} \mathrm{~N}-\mathrm{N}$ & $\mathrm{V}:$ & $\mathrm{Ph}$ & $\mathrm{Me}$ & Et \\
\hline
\end{tabular}

The cholinesterase activity was determined by the manometric method ${ }^{1}$, using acetylcholine, acetyl $\beta$ methylcholine and benzoylcholine chlorides as sub. strates. In all experiments a time-effect was noted : after an initial rise, the pressure decreased to $\mathbf{a}$ minimum after 10-20 min., after which the usual rise was observed, occasionally with slight fluctuation. A second 'wave' (usually after $60 \mathrm{~min}$. or more) was observed when using rabbit brain with or without inhibiting triazoles, or sheep brain with (I) or (II) as inhibitors. Fluctuation of temperature, lack of saturation of the tested mixtures with carbon dioxide or insufficient equilibration were excluded as the causes of this phenomenon.

Triazoles (III), (IV) and (V) had the same effects; most experiments were carried out with (III), which was readily available ${ }^{2}$. The nature of the inhibition was ascertained by plotting inverse rates of carbon dioxide evolution against inverse substrate concentrations. Specific cholinesterase is competitively inhibited by (III) for substrate concentrations of 1-30 mgm. acetyl- $\beta$-methylcholine / $100 \mathrm{ml}$. and triazole/substrate ratios in the range of $0.01-0.05$. At lower concentrations of triazole there is no significant effect; at higher concentrations the enzyme is slightly activated. In a similar range of concentrations of benzoylcholine and triazole/substrate ratios, (III) activates the unspecific cholinesterase ; inactivation occurs at higher triazole concentrations. With acetylcholine as substrate the results were not consistent. In general, lower concentrations of triazole appear to activate, and higher concentrations inactivate, the enzyme system. As the cholinesterase activity of sheep brain is largely due to the specific cholinesterase, it is evident that a factor other than the specific and unspecific cholinesterases is involved in this case. The nature of this factor and the reason for the waves of cholinesterase activity in the stated cases are subjects of further studies.

I wish to thank students of my Department, particularly Mr. R. Naylor and Mr. P. W. Smith, for their assistance in checking some of the results.

\section{Department of Chemistry,}

University of Tasmania, Hobart. July 18.

${ }^{1}$ Ammon, R., Pfligers Arch. ges. Physiol., 233, 486 (1933).

${ }^{2}$ Komzak, A. A., and Polya, J. B., J. App. Chem., 2, 660 (1952),

\section{Double Reduction at the Rosy, or Pink, Locus in Lythrum salicaria}

IT is one of the peculiarities of tetrasomic inheritance, such as we have been investigating for some years past in the purple loosestrife, Lythrum salicaria, that, for any two loci in homologous chromosomes, there are a large number of possible genotypes heterogenic at both loci, and therefore capable of throwing light on the process of genetic recombination. With only two alleles available at each locus, there are indeed nineteen such genotypes, and with the linked loci for short style and for pink, or rosy, flower colour, most of these have been obtained; although the six genotypes triplex for the dominant Short gene have been inaccessible, owing to the illegitimacy of Short by Short matings.

For some years the only genotypes for which any large number of second backcross progenies had been scored were bisimplex coupling, RS/rs/rs/rs, and bisimplex repulsion, Rs/rS/rs/rs. About $1_{\frac{1}{2}}$ per cent of these appeared to come from gametes with two dominant genes, $R$, so indicating ${ }^{2}$ about 6 per cent double reduction at the $R$ locus. The percentage, however, was small, and in consequence a small proportion of alien pollen carrying the $R$ gene could have seriously vitiated the estimated frequency. At the Short locus, for which the corresponding estimate was about $2 \frac{1}{2}$ per cent, the danger of similar contamination is obviated by the bar to illegitimate pollination.

A few years ago, therefore, preparations were made for a direct test of double reduction at the Rosy locus by preparing triplex plants $r S \mid R s / R s / R s$, and in 1954 progenies amounting to 2,057 plants were grown, of which one only proved to be rosy, showing that the previous estimate was much too high. The new estimate would be $\mathbf{0 . 2}$ per cent, if the exceptional plant was accepted as genuinely from the same seed parent as the others, and, as any exception so rare as this is necessarily suspect, the true frequency might be even less.

That the parents of these 2,000 plants were certainly triplex at the Rosy locus has been demonstrated this year, 1955, by growing progenies of a hundred each from a second backcross of sixteen purple Short plants from last year. If the parents were of the genotype presumed, the expectation would be about six duplex, $R S / R s / r s / r s$, and ten simplex in repulsion, $R s / r S / r s / r s$. These were the only two genotypes recognized; there were in fact four and eleven respectively, one progeny being aberrant. The parents were evidently triplex, and the very low frequency of double reduction at the Rosy locus is confirmed.

The case illustrates well the efficacy of employing a second backcross for tetrasomic analysis. With the co-operation of Dr. O. H. Frankel at Canberra and Prof. H. N. Barber at Hobart, it is now hoped that the difficulties of obtaining tetraploids triplex at the short locus also may be overcome in a few years.

R. A. Fushier

Department of Genetics,

University of Cambridge. Aug. 5 .

' Fisher, R. A., Phil. Trans. Roy. Soc., B, 233, 55 (1947).

${ }^{3}$ Fisher, R. A., Proc. Eighth Inter. Cong. Genet., Hereditas, Supp. vol. 225 (1949).

\section{Moncecy and Incompatibility}

IT is customary when classifying breeding systems in Angiosperms to make a clear distinction between three main mechanisms promoting outbreeding. These are incompatibility in hermaphrodites, and separation of the sexes on the same plant (moncecy) or on different plants (dicecy). With incompatibility and dicey outerossing is obligatory. On the othe hand, separation of the sexes on moncecious plants merely decreases the probability of self-fertilization, although this may be further avoided by differences in time of maturity of the two types of flower.

Clearly, however, wherever the sexes mature together on a monoecious plant, an incompatibility system could be of distinct advantage. This possibility 